\title{
Perangkat Pembelajaran Pendekatan STEAM-PJBL pada Tema 2 Selalu Berhemat Energi
}

\section{Ni Putu Linda Krisna Dewi ${ }^{1 *}$, I Gede Astawan², I Made Suariana ${ }^{3}$}

\author{
1,2,3 Universitas Pendidikan Ganesha, Singaraja, Indonesia
}

\section{ART I C L E I N F O \\ Article history: \\ Received May 10, 2021 \\ Revised May 12, 2021 \\ Accepted July 07, 2021 \\ Available online July 25, 2021 \\ Kata Kunci: \\ Perangkat Pembelajaran, STEAM, PjBl \\ Keywords: \\ Learning Tools, STEAM, PjBI

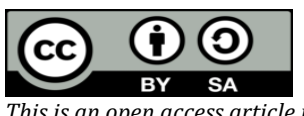 \\ This is an open access article under the CC BY-SA license. \\ Copyright (C) 2021 by Author. Published by Universitas Pendidikan Ganesha.}

A B S TRA C T

\begin{abstract}
A B S T R A K
Masih banyak guru yang belum mampu menciptakan perangat pembelajaran yang inovatif sehingga hal ini berdampak pada hasil belajar siswa yang rendah. Pendekatan dan model pembelajaran yang kurang inovatif akan membuat siswa pasif dalam proses pembelajaran sehingga berdampak pada hasil belajar siswa yang rendah. Penelitian ini bertujuan untuk menciptakan perangkat pembelajaran RPP Berpendekatan STEAMPjBL. Jenis penelitian ini yaitu pengembangan dengan menggunakan model ADDIE. Subjek uji coba penelitian ini yaitu 2 ahli materi, 2 ahli media, 2 ahli desain, 2 praktisi, 4 siswa uji coba perorangan serta 7 siswa uji kelompok kecil. Metode pengumpulan data penelitian yaitu observasi, wawancara, dan kuesioner. Instrumen yang digunakan untuk mengumpulkan data yaitu kuesioner. Penelitian menggunakan teknik analisis deskriptif kualitatif dan teknik analisis kuantitatif. Hasil penelitian yaitu penilaian yang diberikan oleh para ahli rata-rata mendapatkan nilai 3,8 sehingga berada pada kategori sangat baik. Hasil penilaian uji coba produk mendapatkan nilai 3,73 sehingga berada pada kategori sangat baik. Jadi perangkat pembelajaran RPP dan LKPD Berpendekatan STEAM-PjBL mendapatkan kualifikasi sangat baik dan layak diterapkan dalam proses pembelajaran dan produk yang dikembangkan dapat digunakan oleh guru dalam proses pembelajaran. Implikasi penelitian ini dapat membantu siswa dalam belajar serta dapat meningkatkan keaktivan siswa dalam belajar sesuai dengan tuntutan kurikulum 2013.
\end{abstract}

There are still many teachers who have not been able to create innovative learning tools so that this has an impact on low student learning outcomes. Less innovative learning approaches and models will make students passive in the learning process so that the impact on student learning outcomes is low. This study aims to create a lesson plan learning tool with a STEAM-PjBL Approach. This type of research is development using the ADDIE model. The subjects of this research trial were 2 material experts, 2 media experts, 2 design experts, 2 practitioners, 4 students for individual trials and 7 students for small group trials. Research data collection methods are observation, interviews, and questionnaires. The instrument used to collect data is a questionnaire. The research uses qualitative descriptive analysis techniques and quantitative analysis techniques. The results of the study are the assessments given by the experts on average get a score of 3.8 so that they are in the very good category. The results of the product trial assessment get a value of 3.73 so that it is in the very good category. So the RPP and LKPD learning tools with the STEAM-PjBL approach get very good qualifications and deserve to be applied in the learning process and the products developed can be used by teachers in the learning process. The implications of this research can help students in learning and can increase student activity in learning in accordance with the demands of the 2013 curriculum.

\section{PENDAHULUAN}

Perangkat pembelajaran merupakan alat ataupun perlengkapan yang wajib disiapkan guru sebelum proses pembelajaran di kelas di mulai (Afdhal \& Sugiman, 2018; Prayito, 2011). Perangkat adalah alat yang digunakan oleh guru dalam mengajar sehingga memungkinkan guru dan siswa dapat melaksanakan proses pembelajaran dengan baik (Hapsari, Rambita, \& Tindangen, 2018; Nugroho, 2018). Penyusunan perangkat pembelajaran ini merupakan perencanaan dari pembelajaran yang harus dirancang dalam bentuk RPP ataupun LKPD yang mengacu pada standar isi (Nugroho, 2018; Yerizon et al, 2020). LKPD merupakan lembaran yang berisi tugas yang wajib dikerjakan oleh siswa (Angriani et al, 2016). RPP merupakan sebuah rancangan pembelajaran yang nantinya akan diterapkan oleh guru dalam melakukan pembelajaran didalam kelas yang berisikan langkah-langkah proses pembelajaran dari awal hingga akhir pembelajaran untuk mencapai kompetensi dasar yang telah ditetapkan sebelumnya (Mastra, 2019; Wikanengsih, Nofiyanti, \& Permana, 2015). RPP sangat diperlukan oleh guru karena dapat membantu guru dalam melaksanakan kegiatan pembelajaran. Pembelajaran saat ini siswa dituntut untuk lebih aktif daripada guru, sehingga pembelajaran berpusat pada siswa. Hasil belajar yang diharapkan 
tidak hanya sebatas pengetahuan tetapi aspek sosial dan keterampilan perlu dicapai. Kurikulum ini mengharapkan agar siswa yang aktif mencari materi ataupun memecahkan sebuah masalah (Fitri, Saparahayuningsih, \& Agustriana, 2017; Krissandi \& Rusmawan, 2015; Mega, Pudjawan, \& Margunayasa, 2015). Tugas guru hanya mengontrol pembelajaran, memfasilitasi dan mengklarifikasi jika ada materi yang belum dipahami oleh siswa. Selain itu, guru juga memiliki peran dalam menyiapkan perangkat pembelajaran.

Permasalahan saat ini yaitu masih banyak guru belum mampu mengembangkan perangkat pembelajaran (Nugroho, 2018; Wirdaningsih, Arnawa, \& Anhar, 2017). Padahal kurikulum 2013 juga menuntut agar guru mampu mengembangkan perangkat pembelajaran yang dapat meningkatkan semangat belajar. Permasalahan ini juga terjadi di Sekolah Dasar Negeri 3 Banjar Tengah. Berdasarkan hasil observasi ditemukan bahwa saat pembelajaran IPA guru tidak memiliki perangkat pembelajaran IPA yang telah teruji validitas isinya dan perangkat pembelajaran yang dimiliki didapat melalui internet sehingga tidak sesuai dengan kebutuhan siswa. Selain itu, proses pembelajaran konvensional masih diterapkan oleh guru sehingga menimbulkan dampak pada pemahaman siswa yang kurang maksimal berakibat pada penurunan hasil belajar IPA pada siswa. Pendekatan dan model pembelajaran yang kurang inovatif akan membuat siswa pasif dalam proses pembelajaran sehingga tentu saja siswa akan merasa bosan dengan pembelajaran yang berlangsung dan hal ini akan berdampak pada hasil belajar siswa yang rendah (Dewi, Kristiantari, \& Ganing, 2019; Hanifah \& Budiman, 2019).

Solusi yang dapat memecahkan masalah yaitu mengembangkan perangkat pembelajaran yang dapat digunakan guru dalam kegiatan pembelajaran IPA. Perangkat pembelajaran sangat penting disiapkan oleh guru sebelum memulai pembelajaran (Dwitantra, 2015; Udayana, Wirawan, \& Divayana, 2017). Hal ini sangat diperlukan sehingga dalam proses pembelajaran tidak terjadi kendala dan pembelajaran akan lebih tertata dengan baik. Perangkat pembelajaran yang baik akan menghasilkan sebuah pembelajaran yang baik (Rusnilawati, 2016; Wirdaningsih et al., 2017). Perangkat pembelajaran ini meliputi silabus, RPP, buku ajar, LKPD, serta instrument penilaian. Pengembangan perangkat pembelajaran harus disertai dengan keterampilan 4C khususnya pada pembelajaran IPA. Inovasi pembelajaran yang dapat digunakan dalam proses pembelajaran yaitu STEAM. Pendekatan STEAM merupakan pendekatan pembelajaran abad 21 (Bayles et al., 2021; Guevara, Patel, \& Trivedi, 2021). STEAM merupakan pendekatan pembelajaran yang memberikan pada siswa untuk memperluas pengetahuan, sains, humanioran secara bersamaan mengembangkan keterampilan abad 21 seperti berpikir kritis, komunikasi, kepemimpinan, ketangguhan, kreativitas (Sibaweihi et al, 2021; Zharylgassova et al, 2021). Kegiatan pembelajaran yang sesuai dengan STEAM yaitu pembelajaran berbasis proyek. Project based learning melibatkan ssiwa dalam pembelajaran untuk memecahkan salah serta memberikan peluang kepada siswa agar dapat mengekpresikan kreativitasnya sehingga dapat meningkatkan hasil belajarnya (Mahendra, 2017; Mutakinati \& Anwari, 2018; Wijayanti et al, 2016). Pembelajaran ini merupakan strategi dalam memberdayakan siswa untuk memperoleh pengetahuan serta pemahaman baru berdasarkan pengalamannya. Selain itu model PJBL dapat membuat siswa lebih aktif dalam pembelajaran (Laili, Ganefri, \& Usmeldi, 2019; Yulianto, Fatchan, \& Astina, 2017). Selain itu, tujuan pengembangan perangkat pembelajar adalah mempermudah guru untuk melaksanakan proses pembelajaran karena alur kegiatan belajar telah disajikan pada perangkat pembelajaran

Temuan penelitian sebelumnya menyatakan bahwa perancangan perangkat pembelajaran yang baik dapat menciptakan suasana belajar yang baik (Hartini, 2017; Prayito, 2011). Pendekatan STEAM dapat membantu siswa dalam belajar (Revathy et al, 2021; Wang, Liu, \& Zhou, 2021). Project based learning juga dapat meningkatkan hasil belajar siswa (Hartini, 2017; Pratiwi, Ardianti, \& Kanzunnudin, 2018). Belum adanya penelitian mengenai perangkat pembelajaran pendekatan STEAM-PjBL pada tema 2 Selalu berhemat energi. Kelebihan perangkat pembelajaran yang akan dikembangkan yaitu perangkat ini akan menerapkan model dan pendekatan pembelajaran inovatif yang dapat merangsang keaktivan siswa dalam belajar IPA. Perangkat pembelajaran yang akan dikembangkan terintegrasi dengan STEAM dan menggunakan sintak model PjBl. Tujuan penelitian ini yaitu menciptakan perangkat pembelajaran pendekatan STEAM-PjBL pada tema 2 Selalu berhemat energi. Perangkat pembelajaran yang dikembangkan dapat membantu siswa dalam belajar serta dapat meningkatkan keaktivan siswa dalam belajar sesuai dengan tuntutan kurikulum 2013.

\section{METODE}

Jenis penelitian ini yaitu penelitian pengembangan (Research and Development). Produk yang dikembangkan dalam penelitian ini yaitu pengembangan perangkat pembelajaran, yaitu terdiri dari rencana pelaksanaan pembelajaran (RPP) dan Lembar Kerja Peserta Didik (LKPD). Prosedur yang digunakan dalam mengembangkan produk yaitu ADDIE yang meliputi tahap analisis, desain, 
pengembangan, implementasi, dan evaluasi (Tegeh \& Kirna, 2010) yang di tunjukkan pada gambar 1. Uji produk yang dilakukan yaitu 2 orang ahli materi IPA, 2 orang ahli media pembelajaran, 2 orang ahli desain pembelajaran, 2 orang ahli praktisi (guru). Metode pengumpulan data penelitian yaitu observasi, wawancara, dan kuesioner. Instrmen yang digunakan untuk mengumpulkan data yaitu kuesioner. Adapun rancangan desain pengembangan tersaji pada gambar 1 dan kisi-kisi instrument tersaji pada tabel 1, 2, 3 dan tabel 4.

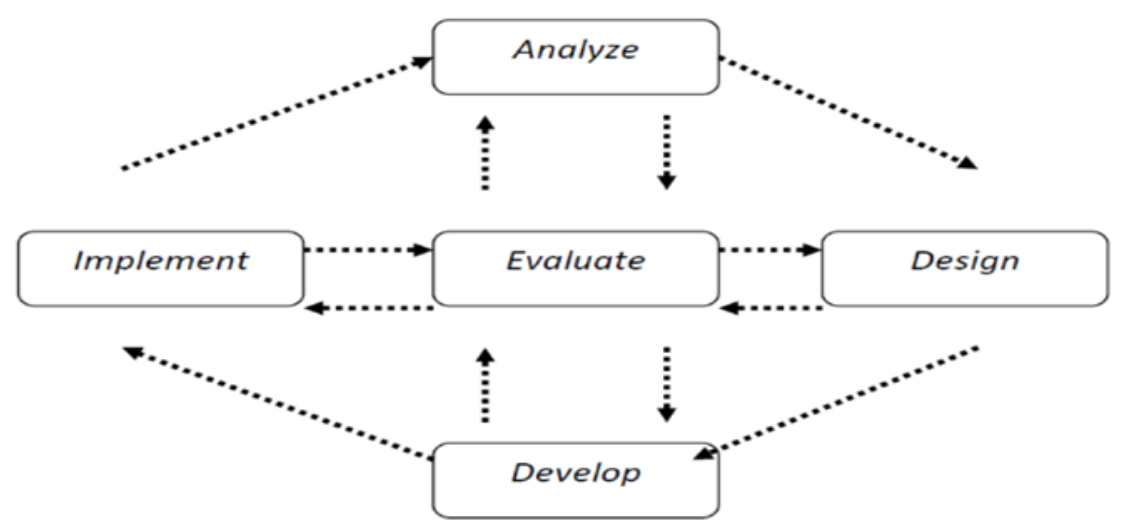

Gambar 1. Desain Pengembangan Perangkat Pembelajaran STEAM-PjBL

Tabel 1. Kisi-Kisi Instrumen Validasi RPP Berpendekatan STEAM-PjBL Ahli Materi

\begin{tabular}{|c|c|c|c|c|}
\hline No & Aspek & Indikator & $\begin{array}{c}\text { Jumlah } \\
\text { Butir }\end{array}$ & $\begin{array}{c}\text { Nomor } \\
\text { Butir }\end{array}$ \\
\hline \multirow[t]{3}{*}{1} & $\begin{array}{l}\text { Kelengkapan serta } \\
\text { keruntutan RPP sesuai }\end{array}$ & $\begin{array}{l}\text { Kelengkapan RPP sesuai dengan } \\
\text { Permendikbud Nomor } 22 \text { Tahun } 2016\end{array}$ & & 1 \\
\hline & Permendikbud Nomor 22 & Keruntutan komponen RPP sesuai & 2 & \\
\hline & Tahun 2016 & $\begin{array}{l}\text { dengan Permendikbud Nomor } 22 \\
\text { Tahun } 2016\end{array}$ & & 2 \\
\hline \multirow[t]{2}{*}{2} & Materi Pokok & Materi pokok sesuai dengan & & \\
\hline & & $\begin{array}{l}\text { kompetensi dasar yang } \\
\text { ditentukan }\end{array}$ & 1 & 3 \\
\hline 3 & Alokasi Waktu & $\begin{array}{l}\text { Alokasi waktu sesuai dengan keperluan } \\
\text { yang dirancang untuk pencapaian } \\
\text { kompetensi dasar }\end{array}$ & 1 & 4 \\
\hline 4 & Tujuan Pembelajaran & $\begin{array}{l}\text { Perumusan tujuan pembelajaran } \\
\text { berdasarkan indikator pencapaian } \\
\text { kompetensi }\end{array}$ & 1 & 5 \\
\hline \multirow[t]{3}{*}{5} & $\begin{array}{l}\text { Kompetensi dasar dan } \\
\text { indikator pencapaian }\end{array}$ & $\begin{array}{l}\text { Kompetensi dasar sesuai dengan } \\
\text { silabus }\end{array}$ & & 6 \\
\hline & kompetensi & $\begin{array}{l}\text { Perumusan indikator sesuai dengan } \\
\text { kompetensi dasar }\end{array}$ & 3 & 7 \\
\hline & & $\begin{array}{l}\text { Rumusan indikator menggunakan Kata } \\
\text { Kerja Oprasional (KKO) }\end{array}$ & & 8 \\
\hline 6 & Materi pembelajaran & $\begin{array}{l}\text { Materi pembelajaran memuat konsep, } \\
\text { fakta, prinsip dan prosedur yang } \\
\text { relevan dengan apa yang sudah } \\
\text { dirumusan indikator }\end{array}$ & 1 & 9 \\
\hline 7 & Pendekatan Pembelajaran & $\begin{array}{l}\text { Pendekatan pembelajaran yang } \\
\text { digunakan yaitu pendekatan STEAM } \\
\text { yang bisa dipadukan dengan model yang } \\
\text { digunakan. }\end{array}$ & 1 & 10 \\
\hline 8 & Metode Pembelajaran & $\begin{array}{l}\text { Metode pembelajaran yang digunakan } \\
\text { disesuikan dengan model pembelajaran } \\
\text { yang digunakan yaitu dengan metode } \\
\text { diskusi, tanya jawab, dan proyek }\end{array}$ & 1 & 11 \\
\hline 9 & Media pembelajaran & Ketepatan pemilihan media & 2 & 12 \\
\hline
\end{tabular}




\begin{tabular}{|c|c|c|c|c|}
\hline No & Aspek & Indikator & $\begin{array}{c}\text { Jumlah } \\
\text { Butir }\end{array}$ & $\begin{array}{c}\text { Nomor } \\
\text { Butir }\end{array}$ \\
\hline \multirow{4}{*}{10} & \multirow{4}{*}{ Sumber belajar } & pembelajaran & \multirow{6}{*}{1} & \\
\hline & & $\begin{array}{l}\text { Kesesuaian media pembelajaran } \\
\text { dengan metode pembelajaran }\end{array}$ & & 13 \\
\hline & & Sumber belajar yang digunakan & & \\
\hline & & $\begin{array}{l}\text { disesuikan dengan tujuan pembelajaran } \\
\text { yang dirumuskan }\end{array}$ & & 14 \\
\hline \multirow[t]{4}{*}{11} & \multirow{4}{*}{$\begin{array}{l}\text { Langkah-langkah } \\
\text { pembelajaran }\end{array}$} & Kesesuaian langkah-langkah & & \\
\hline & & $\begin{array}{l}\text { pembelajaran dengan menggunakan } \\
\text { pendekatan STEAM-PjBL }\end{array}$ & & 15 \\
\hline & & Keruntutaan dari langkah-langkah & 2 & \\
\hline & & $\begin{array}{l}\text { pembelajaran sesuai pendekatan STEAM- } \\
\text { PjBL }\end{array}$ & & 16 \\
\hline \multirow[t]{2}{*}{12} & \multirow{2}{*}{$\begin{array}{l}\text { Penilaian hasil } \\
\text { pembelajaran }\end{array}$} & Ketepatan memilih teknik penilaian & \multirow[b]{2}{*}{2} & 17 \\
\hline & & $\begin{array}{l}\text { Ketepatan memilih bentuk dan } \\
\text { instrumen penilaian }\end{array}$ & & 18 \\
\hline 13 & Tata bahasa & $\begin{array}{l}\text { Penggunaan kalimat berdasarkakn EYD } \\
\text { Kalimat mudah dipahami }\end{array}$ & 2 & $\begin{array}{l}19 \\
20\end{array}$ \\
\hline
\end{tabular}

(Sumber: dimodifikasi dariPermendikbud, 2016)

Tabel 2. Kisi-Kisi Instrumen validasi LKPD Berpendekatan STEAM-PjBL Ahli Materi

\begin{tabular}{|c|c|c|}
\hline No & Aspek & Indikator \\
\hline 1 & Identitas dari LKPD & Kelengkapan dari identitas LKPD \\
\hline 2 & Petunjuk kerja LKPD & Kejelasan dari petunjuk kerja LKPD \\
\hline 3 & Tujuan Pembelajaran & $\begin{array}{l}\text { Tujuan pembelajaran sesuai Indikator Pencapaian Kompetensi (IPK) } \\
\text { dengan format ABCD }\end{array}$ \\
\hline 4 & Materi Pembelajaran & $\begin{array}{l}\text { Kesesuaian materi pembelajaran dengan tujuan pembelajaran } \\
\text { Kelengkapan materi pembelajaran } \\
\text { Keterbaharuan materi pembelajaran }\end{array}$ \\
\hline 5 & $\begin{array}{l}\text { Kegiatan dan langkah- } \\
\text { langkah pembelajaran }\end{array}$ & $\begin{array}{l}\text { Kegiatan pembelajaran dilakukan secara sistematis } \\
\text { Kemudahan dalam langkah-langkah pembelajaran }\end{array}$ \\
\hline 6 & Alokasi Waktu & Alokasi waktu yang direncanakan sesuai dengan materi pokok \\
\hline 7 & $\begin{array}{l}\text { Penggunaan dan tata } \\
\text { Bahasa }\end{array}$ & $\begin{array}{l}\text { Bahasa yang digunakan mudah dipahami dan penggunakan tata bahasa } \\
\text { sesui dengan EYD }\end{array}$ \\
\hline
\end{tabular}

Tabel 3. Kisi-Kisi Instrumen validasi LKPD Berpendekatan STEAM-PjBL Ahli Media

\begin{tabular}{ll}
\hline \multicolumn{1}{c}{ Aspek } & \multicolumn{1}{c}{ Indikator } \\
\hline Tampilan & Kemenarikan sampul/cover LKPD \\
& Kesesuaian tampilan LKPD dengan karakteristik peserta didik \\
Teks & Kejelasan pemilihan jenis dan ukuran teks dalam LKPD \\
& Huruf dalam LKPD mudah dibaca dan jelas \\
Gambar & Huruf dalam LKPD sesuai dan konsisten \\
& Gambar yang digunakan pada LKPD jelas dan mudah dimengerti peserta \\
& didik \\
Warna & Kemenarikan gambar pada LKPD \\
& Kemenarikan komposisi warna pada LKPD \\
Tata Letak & Teharmonisan setiap warna pada LKPD \\
& Tata letak teks konsisten di setiap halaman LKPD \\
& dengan yang lainnya \\
\hline
\end{tabular}

(Sumber: dimodifikasi dari Permendikbud, 2016) 
Tabel 4. Kisi-Kisi Instrumen validasi LKPD Berpendekatan STEAM-PjBL Ahli Desain

\begin{tabular}{ll}
\hline \multicolumn{1}{c}{ Aspek } & \multicolumn{1}{c}{ Indikator } \\
\hline Tampilan & Kesesuaian desain LKPD dalam memotivasi minat belajar peserta didik \\
Teks & Kejelasan teks yang digunakan \\
& Kejelasan tulisan/pengetikan \\
& Kekonsistensi penggunaan spasi dan pengetikan materi \\
Gambar & Ketepatan penempatan gambar-gambar ilustrasi \\
& Kesesuaian proporsi gambar pada LKPD \\
Motivasi & Pemberian motivasi belajar \\
Evaluasi & Ketepatan cara penyajian soal \\
& Kejelasan urutan penyajian soal.
\end{tabular}

(Sumber: dimodifikasi dari Permendikbud, 2016)

Pada penelitian ini uji instrumen yang digunakan yaitu uji validitas isi. Uji validitasi isi dilakukan dengan menggunakan rumus Gregory dan dibuatkan tabulasi silang. Penelitian menggunakan teknik analisis deskriptif kualitatif dan teknik analisis kuantitatif. Teknik analisis deskriptif kualitatif digunakan untuk mengolah data hasil review dari para ahli. Teknik analisis deskriptif kuantitatif digunakan untuk mengolah data berupa angka diperoleh melalui lembar penilaian

\section{HASIL DAN PEMBAHASAN}

Hasil

Pada penelitian ini, model yng digunakan yaitu model ADDIE yang terdiri dari 5 tahapan yaitu analyze, design, development, implementation, evaluation. Pertama yaitu analisis. Pada tahap ini dilakukan untuk menentukan kebutuhan belajar dan mengidentifikasi permasalahan yang terjadi pada siswa dan proses pembelajaran di sekolah. Tahap analisis terdiri dari tiga bagian yaitu analisis kurikulum, kebutuhan, dan karakteristik siswa. Analisis kurikulum dimulai dengan menganalisis KI, KD, dan indikator pencapaian kompetensi. Kemudian, KI, KD, dan indikator ini disesuaikan dengan buku guru dan buku siswa. Untuk indikator dapat ditingkatkan agar siswa terbiasa berpikir tingkat tinggi namun tetap disesuaikan dengan KD. Hasil analisis kebutuhan yaitu guru sangat membutuhkan RPP dan LKPD yang inovatif serta sudah teruji validitas isinya untuk dibelajarkan di Kelas IV Sekolah Dasar. Hasil analisis karakteristik siswa yaitu Siswa juga senang melakukan pembelajaran yang berisi percobaan atau membuat suatu proyek.

Kedua yaitu desain. Pada tahap ini merancang produk yang dikembangkan yaitu perangkat pembelajaran berpendekatan STEAM-PjBL pada Tema 2 Selalu Berhemat Energi Muatan IPA Kelas IV Sekolah Dasar berdasarkan hasil analisis. Tahap perancangan dilakukan dengan menyusun instrumen penilaian perangkat pembelajaran berupa RPP dan LKPD serta rancang bangun pengembangan perangkat pembelajaran berupa RPP dan LKPD Berpendekatan STEAM-PjBL. Rancangan perangkat pembelajaran yang dikembangkan dalam penelitian pengembangan ini yaitu rancangan perangkat pembelajaran RPP dan LKPD berpendekatan STEAM-PjBL untuk kelas 4 sekolah dasar pada muatan IPA tema 2 selalu berhemat energi. Untuk perangkat pembelajaran berupa RPP berpendekatan STEAM-PjBL terdiri dari beberapa bagian yaitu sampul, identitas RPP, Kompetensi Inti (KI), Kompetensi Dasar (KD) dan Indikator Pencapaian Kompetensi (IPK), tujuan pembelajaran, materi pembelajaran, Pendekatan, Model, dan Metode Pembelajaran, Media, Alat dan Bahan, dan Sumber Belajar, langkah-langkah pembelajaran, penialaian hasil pembelajaran. Kemudian, untuk perangkat pembelajaran berupa LKPD berpendekatan STEAM-PjBL terdiri dari beberapa bagian yaitu, sampul LKPD, identitas LKPD, tujuan pembelajaran, petunjuk kerja, materi pembelajaran, alat dan bahan, kegiatan dan langkah-langkah pembelajaran evaluasi. Adapun desain pengembangan dapat dilihat pada gambar 2.

Ketiga yaitu pengembangan. Pada tahap pengembangan, perangkat pembelajaran mulai dikembangkan sesuai hasil dari tahap analisis dan perancangan. Pengembangan RPP dan LKPD berpendekatan STEAM-PjBL dilakukan sesuai rancangan RPP dan LKPD berpendekatan STEAM-PjBL yang ada pada tahap desain. Untuk perangkat pembelajaran berupa RPP berpendekatan STEAM-PjBL terdiri dari beberapa bagian yaitu, sampul, identitas RPP, Kompetensi Inti (KI), Kompetensi Dasar (KD) dan Indikator Pencapaian Kompetensi (IPK), tujuan pembelajaran, materi pembelajaran, Pendekatan, Model, dan Metode Pembelajaran, Media, Alat dan Bahan, dan Sumber Belajar, langkah-langkah pembelajaran, penialaian hasil pembelajaran. Kemudian, untuk perangkat pembelajaran berupa RPP berpendekatan STEAM-PjBL terdiri dari beberapa bagian yaitu, sampul LKPD, identitas LKPD, tujuan pembelajaran, petunjuk kerja, materi pembelajaran, (6) alat dan bahan, kegiatan dan langkah-langkah pembelajaran, evaluasi. Hasil pengembangan tersaji pada gambar 3. 

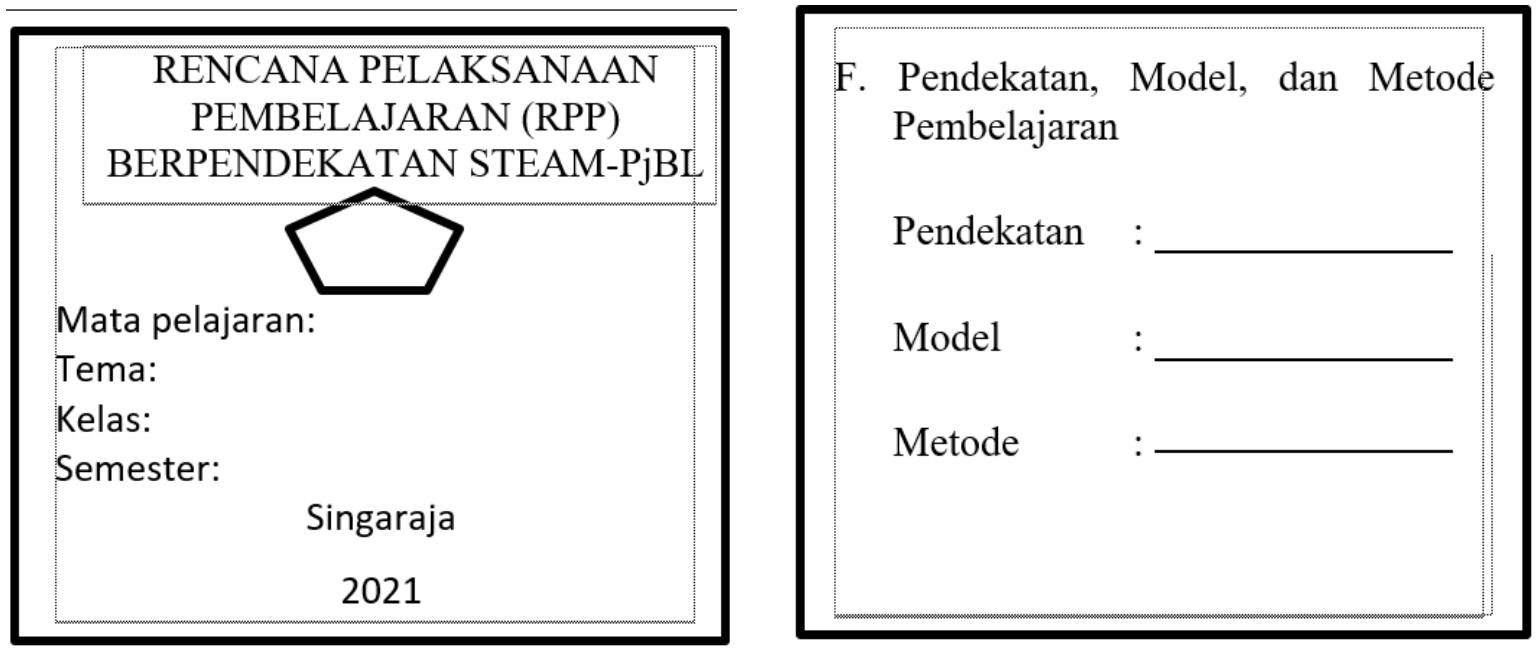

Gambar 2. Desain Perangkat Pembelajaran RPP Pendekatan STEAM-PjBL
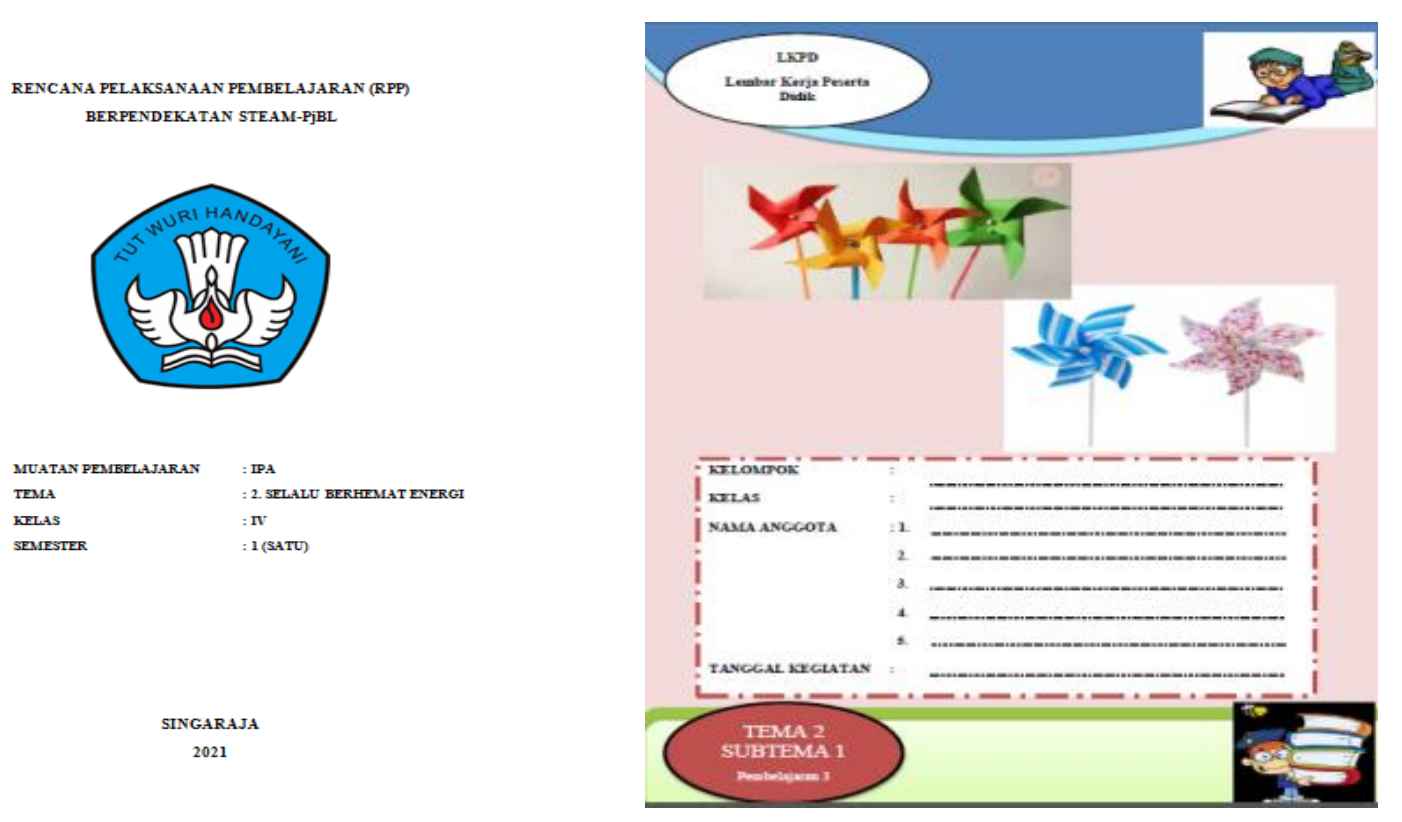

Gambar 3. Perangkat Pembelajaran RPP Pendekatan STEAM-PjBL

Selanjutnya produk RPP dan LKPD berpendekatan STEAM-PjBL yang telah dikembangkan, kemudian di evaluasi oleh beberapa ahli yaitu 2 orang ahli materi IPA, 2 orang ahli media pembelajaran, 2 orang ahli desain pembelajaran, 2 orang ahli praktisi (guru). Hasil penialain produk disajikan pada tabel 5.

Tabel 5. Hasil Penilaian Perangkat Pembelajaran RPP Pendekatan STEAM-PjBL

\begin{tabular}{|c|c|c|c|c|}
\hline No & Ahli & Kategori & Nilai & Kualifikasi \\
\hline 1 & Ahli Materi & Produk RPP & 3,81 & Sangat Baik \\
\hline 2 & Ahli Materi & Produk LKPD & 3,82 & Sangat Baik \\
\hline 3 & Ahli Media & Produk LKPD & 3,76 & Sangat Baik \\
\hline 4 & Ahli Desain & Produk LKPD & 3,85 & Sangat Baik \\
\hline 5 & Uji Coba Perorangan & Produk LKPD & 3,77 & Sangat Baik \\
\hline 6 & Uji Coba Kelompok Kecil & Produk LKPD & 3,68 & Sangat Baik \\
\hline
\end{tabular}


Berdasarkan penilaian yang diberikan oleh ahli materi mengenai produk RPP yang dikembangkan mendapatkan nilai 3,81 sehingga masuk kedalam kualifikasi sangat baik. Hasil penilaian yang diberikan oleh ahli materi mengenai produk LKPD yang dikembangkan mendapatkan nilai 3,82 sehingga masuk kedalam kualifikasi sangat baik. Hasil penilaian yang diberikan oleh ahli media mengenai produk LKPD yang dikembangkan mendapatkan nilai 3,76 sehingga masuk kedalam kualifikasi sangat baik. Hasil penilaian yang diberikan oleh ahli desain mengenai produk LKPD yang dikembangkan mendapatkan nilai 3,85 sehingga masuk kedalam kualifikasi sangat baik. Hasil uji coba perorangan nilai yang didapatkan yaitu 3,77 sehingga masuk kedalam kualifikasi sangat baik. Hasil uji coba kelompok kecil nilai yang didapatkan yaitu 3,68 sehingga masuk kedalam kualifikasi sangat baik. Beberapa masukan yang diberikan oleh para ahli untuk menyempurnakan perangkat pembelajaran tersaji pada tabel 6 .

Tabel 6. Hasil Revisi Ahli untuk Perangkat Pembelajaran RPP Berpendekatan STEAM-PjBL

\begin{tabular}{|c|c|c|c|c|}
\hline No. & $\begin{array}{c}\text { Masukan, Saran, dan } \\
\text { Komentar }\end{array}$ & \multicolumn{3}{|c|}{ Hasil Revisi } \\
\hline \multirow[t]{4}{*}{1.} & \multirow{4}{*}{$\begin{array}{l}\text { IPK masih perlu } \\
\text { ditingkatkan, untuk } \\
\text { membiasakan siswa } \\
\text { berfikir tingkat tinggi. }\end{array}$} & \multicolumn{3}{|c|}{$\begin{array}{l}\text { C. Kompetensi Dasar dan Indikator Pencapaian Kompetensi } \\
\text { Muatan IPA }\end{array}$} \\
\hline & & \multicolumn{2}{|r|}{ Kompetensi dasar (KD) } & $\begin{array}{l}\text { Indikator Pencapaian Kompetensi } \\
\text { (IPK) }\end{array}$ \\
\hline & & \multicolumn{2}{|r|}{$\begin{array}{l}\text { Mengidentifikasi berbagai } \\
\text { sumber energi, perubahan } \\
\text { bentuk energi, dan sumber } \\
\text { energi alternatif (angin, air, } \\
\text { matahari, panas bumi, bahan } \\
\text { bakar organik, dan nuklir) } \\
\text { dalam kehidupan sehari-hari. }\end{array}$} & $\begin{aligned} \text { 3.5.1 } & \begin{array}{l}\text { Memaparkan pengertian energi } \\
\text { angin. }\end{array} \\
& \text { (Mengemukakan }=\mathbf{C 3} \text { ) } \\
\text { 3.5.2 } & \text { Menemukan perubahan bentuk } \\
& \text { energi angin dalam kehidupan } \\
& \text { sehari-hari. } \\
& \text { (Menemukan }=\mathbf{C 4 )} \\
\text { 3.5.3 } & \text { Menemukan manfaat energi } \\
& \text { angin dalam kehidupan sehari- } \\
& \text { hari. } \\
& (\text { Menemukan }=\mathbf{C 4})\end{aligned}$ \\
\hline & & & $\begin{array}{l}\text { Menyajikan laporan hasil } \\
\text { pengamatan dan penelusuran } \\
\text { informasi tentang berbagai } \\
\text { perubahan bentuk energi. }\end{array}$ & $\begin{array}{llr}\text { 4.5.1 } & \begin{array}{l}\text { Menyajikan laporan hasil } \\
\text { pengamatan }\end{array} & \text { tentang } \\
& \text { perubahan bentuk energi } \\
& \text { angin. } \\
& \text { (Menyajikan }=\mathbf{C 5} \text { ) } & \\
\end{array}$ \\
\hline
\end{tabular}

2. Pada LKPD terlihat jelas sintak PjBL jadi semua fase harus dicantumkan

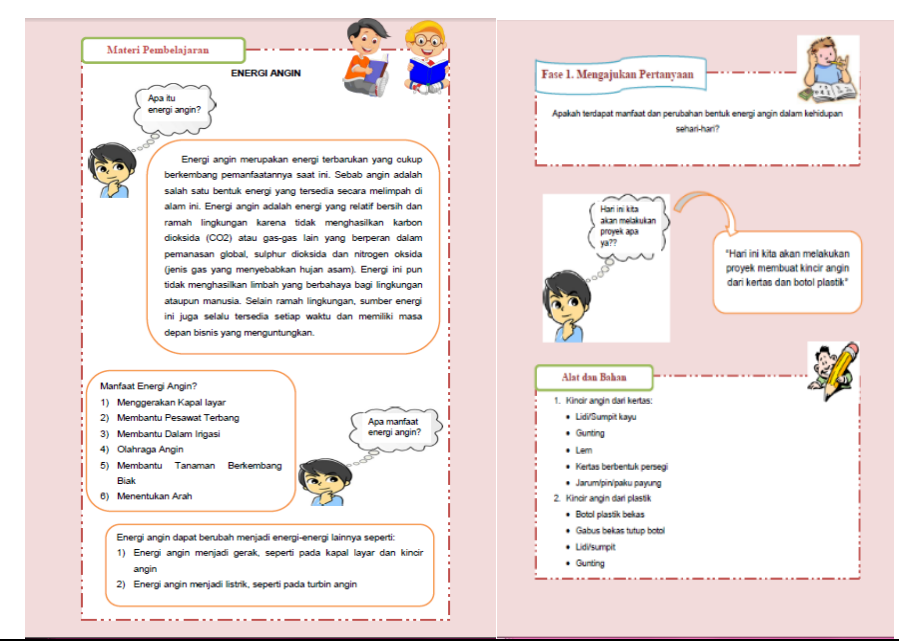

Berdasarkan hasil analisis data, produk yang dikembangkan berupa perangkat pembelajaran RPP Berpendekatan STEAM-PjBL mendapatkan kualifikasi sangat baik sehingga layak diterapkan dalam proses pembelajaran. Hal ini disebabkan oleh beberapa faktor yaitu sebagai berikut. Pertama, perangkat pembelajaran RPP Berpendekatan STEAM-PjBL layak diterapkan dalam proses pembelajaran karena dapat meningkatkan semangat siswa dalam belajar. Perangkat pembelajaran yang dikembangkan menuntut siswa untuk lebih aktif dalam memecahkan masalah karena menggunakan pendekatan $\mathrm{PjBl}$. $\mathrm{PjBl}$ dapat memudahkan siswa dalam belajar sehingga dapat meningkatkan motivasi siswa dalam belajar (Hartini, 2017; Mustika \& Ain, 2020; Pratiwi et al., 2018). LKPD yang dikembangkan juga dapat meningkatkan semangat siswa dalam belajar. Hal ini dilihat dari aspek tampilan, aspek teks, aspek gambar, aspek warna, dan aspek tata letak. Dengan menggunakan perangkat pembelajaran berupa LKPD berpendekatan STEAM-PjBL dapat memotivasi serta meningkatkan kreativitas siswa dalam proses 
pembelajaran. pemilihan warna ataupun gambar yang menarik dapat meningkatkan motivasi siswa dalam belajar (Darmayasa, Suara, \& Manuaba, 2013; Handayani \& Abadi, 2020; Pujayanti, Murda, \& Wibawa, 2013). Pendekatan ini sangat cocok digunakan untuk meningkatkan perkembangan siswa terutama keterampilan berkomunikasi pada siswa serta kemampuan berpikir kritis siswa (Gunawan, Sahidu, Harjono, \& Suranti, 2017; Zeptyani \& Wiarta, 2020).

Kedua, perangkat pembelajaran RPP Berpendekatan STEAM-PjBL layak diterapkan dalam proses pembelajaran karena dapat memudahkan siswa dalam belajar. pembelajaran model PJBL akan membuat siswa memperoleh pengetahuan dan pemahaman barunya berdasarkan pengalamannya (Izati, Wahyudi, \& Sugiyarti, 2018; Laili et al., 2019). Model ini adalah model inovatif yang mengajak seluruh siswa terlibat dalam suatu proyek sehingga akan menghasilkan sebuah produk. PjBL mampu mengembangkan kreativitas siswa dalam pembelajaran sehingga memudahkan siswa dalam memahami pembelajaran (Wijayanti et al., 2016; Yulianto et al., 2017). Model pembelajaran PjBL berpusat pada siswa sehingga cocok diterapkan pada abad 21. Siswa akan merasakan keikutsertaannya dalam pembelajaran sehingga berakibat pada meningkatkan pemahaman siswa terhadap materi yang diberikan oleh guru khususnya pada materi pelajaran IPA. Hal ini juga menyebabkan siswa aktif dalam belajar.

Ketiga, perangkat pembelajaran RPP Berpendekatan STEAM-PjBL layak diterapkan dalam proses pembelajaran karena dapat menciptakan suasana belajar yang menyenangkan. Pembelajaran ini memberdayakan guru dalam pembelajaran berbasis proyek yang melibatkan disiplin ilmu seperti matematika, teknologi, sains, dan seni (Hidayat et al, 2019; Wijanarko, Supardi, \& Marwoto, 2017). Hal ini yang menumbuhkan lingkungan belajar yang menyenangkan karena seluruh siswa ikut berkontribusi. Pendekatan STEAM ini pendekatan yang mengajak siswa berkontribusi secara langsung dalam pembelajaran sehingga mengembangkan seluruh keterampilan yang dimiliki oleh siswa (Nkulikiyinka et al, 2020; Thuneberg, Salmi, \& Bogner, 2018). Keterampilan yang dikembangkan ini nantinya akan berguna dalam kehidupan siswa. RPP yang dikembangkan juga merancang setiap pembelajaran yang berisi langkah-langkah pembelajaran dari awal hingga akhir secara sistematis sehingga pembelajaran dapat berjalan dengan baik. selain itu dalam pembelajaran, juga menggunakan LKPD yang mempermudah guru dalam mengajar serta memberikan peluang pada siswa untuk aktid dalam pembelajaran sehingga menciptakan suasana belajar yang menyenangkan.

Temuan penelitian sebelumnya yaitu perangkat pembelajaran yang baik akan memudahkan siswa dalam belajar (Hapsari et al., 2018; Nugroho, 2018). Penelitian lainnya juga mengungkapkan bahwa pendekatan STEAM dapat meningkatkan motivasi siswa dalam belajar (Nkulikiyinka et al., 2020; Revathy et al., 2021). Model PjBL juga mampu merangsang keatifan belajar pada siswa (Elisabet, Relmasira, \& Hardini, 2019; Pratiwi et al., 2018). Kelebihan dari perangkan pembelajaran yang dikembangkan yaitu perangkat ini dikembangkan sesuai dengan karakteristik siswa dan materi pembelajaran sehingga sesuai. Selain itu, Guru dapat mengorganisasi fasilitas, perlengkapan, alat bantu pengajaran, waktu dan isi dalam rangka untuk mencapai tujuan belajar seefektif mungkin serta menghubungkan tujuan dan prosedur kepada tujuan keseluruhan dari mata pelajaran yang diajarkan. Kelemahan perangkat pembelajaran yang dikembangkan yaitu perangkat pembelajaran ini hanya dapat digunakan untuk pembelajaran pada topik selalu berhemat energi sehingga untuk pembelajaran lainnya guru harus membuat perangkat pembelajaran baru. Selain itu perangkat pembelajaran yang dikembangkan belum belum teruji efektivitasnya, namun tetap layak digunakan karena telah dilakukan uji validitas. Implikasi penelitian ini yaitu adanya perangkat pembelajaran berpendekatan STEAM-PjBL ini guru dapat melakukan pembelajaran yang lebih sistematis dan inovatif. Kemudian, dengan pendekatan STEAM-PjBL siswa dapat mengembangkan kreatifitasnya sehingga siswa akan lebih aktif dan semangat dalam proses pembelajaran

\section{SIMPULAN}

Perangkat pembelajaran RPP pendekatan STEAM-PjBL mendapatkan kategori sangat baik. Perangkat pembelajaran RPP pendekatan STEAM-PjBL layak digunakan dalam proses pembelajaran. Perangkat ini dapat memudahkan guru dalam mengajar sehingga tujuan pembelajaran dapat tercapai. Direkomendasikan agar guru menggunakan perangkat pembelajaran pendekatan STEAM-PjBL sehingga proses pembelajaran lebih menarik.

\section{DAFTAR PUSTAKA}

Afdhal, M., \& Sugiman, S. (2018). Pengembangan perangkat pembelajaran berbasis reciprocal teaching berorientasi pada antusiasme dan kemampuan berpikir kritis siswa. Pythagoras: Jurnal Pendidikan Matematika, 12(2). https://doi.org/https://doi.org/10.21831/pg.v12i2.17716.

Angriani, A. D., Bernard, B., Nur, R., \& Nurjawahirah, N. (2016). Meningkatkan Kemampuan Pemecahan Masalah Melalui Pembelajaran Kooperatif Think-Talk-Write Pada Peserta Didik Kelas Viii1 Mtsn 
Model Makassar. MaPan: Jurnal Matematika Dan Pembelajaran, 4(1), 11-28. https://doi.org/10.24252/mapan.2016v4n1a2.

Bayles, J., Peterson, A. D., Pitts, S. J., Bian, H., Burkholder, S., Hegde, A. V., \& Stage, V. C. (2021). Food-Based Science, Technology, Engineering, Arts, and Mathematics (STEAM) Learning Activities May Reduce Decline in Preschoolers' Skin Carotenoid Status. Journal of Nutrition Education and Behavior, 53(4). https://doi.org/10.1016/j.jneb.2020.10.017.

Darmayasa, I. W. G. S., Suara, I. M., \& Manuaba, I. B. S. (2013). Penerapan Model Pembelajaran Kooperatif Tipe Two Stay Two Strayberbantuan Media Gambar Untuk Meningkatkan Motivasi Dan Hasil Belajar PKn. MIMBAR PGSD Undiksha, 1(1). http://dx.doi.org/10.23887/jjpgsd.v1i1.922.

Dewi, N. N. K., Kristiantari, M. . R., \& Ganing, N. N. (2019). Pengaruh Model Pembelajaran Picture And Picture Berbantuan Media Visual Terhadap Keterampilan Menulis Bahasa Indonesia. Journal of Education Technology, 3(4). http://dx.doi.org/10.23887/jet.v3i4.22364.

Dwitantra, P. (2015). Pengembangan Perangkat Pembelajaran Model Discovery \& Course Review Horay (Disco) Pada Pembelajaran Lagu Daerah Nusantara Kelas 5 Sekolah Dasar Berbasis Kurikulum 2013. Journal of Primary Education, 3(2). https://doi.org/10.15294/jpe.v3i2.6966.

Elisabet, E., Relmasira, S. C., \& Hardini, A. T. A. (2019). Meningkatkan Motivasi dan Hasil Belajar IPA dengan Menggunakan Model Pembelajaran Project Based Learning (PjBL). Journal of Education Action Research, 3(3), 285. https://doi.org/10.23887/jear.v3i3.19451.

Fitri, Saparahayuningsih, \& Agustriana. (2017). Perencanaan Pembelajaran Kurikulum 2013 Pendidikan Anak Usia Dini. Jurnal Ilmiah Potensia, 2(1). https://doi.org/https://doi.org/10.33369/jip.2.1.113.

Guevara, J. L., Patel, R., \& Trivedi, J. (2021). Optimization of steam injection in SAGD using reinforcement learning. Journal of Petroleum Science and Engineering, 4. https://doi.org/10.1016/j.petrol.2021.108735.

Gunawan, G., Sahidu, H., Harjono, A., \& Suranti, N. M. Y. (2017). The effect of project based learning with virtual media assistance on student's creativity in physics. Jurnal Cakrawala Pendidikan, 1(2). https://doi.org/10.21831/cp.v36i2.13514.

Handayani, R., \& Abadi, I. B. G. S. (2020). Pengaruh Model Pembelajaran Langsung Berbantuan Media Gambar Terhadap Kompetensi Pengetahuan Matematika Siswa Kelas IV SD. Mimbar Ilmu Undiksha, 25(1), 120-131. http://dx.doi.org/10.23887/mi.v25i1.24767.

Hanifah, \& Budiman. (2019). Pengaruh Model Open Ended Problem Berbantu Media Kotak Telur Pelangi ( Kotela ) Terhadap Hasil Belajar. Journal of Education Technology., 3(3), 1-137. http://dx.doi.org/10.23887/jet.v3i3.21734.

Hapsari, T. R., Rambita, V. M. M., \& Tindangen, M. (2018). Analisis Permasalahan Guru Terkait Perangkat Pembelajaran Berbasis Model Examples Non Examples dan Permasalahan Siswa Terkait Hasil Belajar Biologi di SMA. Jurnal Pendidikan: Teori, Penelitian, Dan Pengembangan, 3(2). https://doi.org/10.17977/jptpp.v3i2.10529.

Hartini, A. (2017). Pengembangan Perangkat Pembelajaran Model Project Based Learning Untuk Meningkat Kemampuan Berpikir Kritis Siswa Sekolah Dasar. Jurnal Pendidikan Dan Pembelajaran Di Sekolah Dasar, 1(2). http://dx.doi.org/10.30651/else.v1i2a.1038.

Hidayat, S., Agusta, E., Siroj, R. A., \& Hastiana, Y. (2019). Lesson Study \& Project Based Learning sebagai Upaya Membentuk Forum Diskusi dan Perbaikan Kualitas Pembelajaran Guru IPA. Jurnal Pengabdian Kepada Masyarakat, 4(2). https://doi.org/10.22146/jpkm.31423.

Izati, Wahyudi, \& Sugiyarti, M. (2018). Project Based Learning Berbasis Literasi untuk Meningkatkan Hasil Belajar Tematik. Jurnal Pendidikan, 3(9), 1122-1127. http://dx.doi.org/10.17977/jptpp.v3i9.11508.

Krissandi, \& Rusmawan. (2015). Kendala Guru Sekolah Dasar Dalam Implementasi Kurikulum 2013. Jurnal Pendidikan Indonesia, 34(3), 457-467. https://doi.org/10.21831/cp.v3i3.7409.

Laili, Ganefri, \& Usmeldi. (2019). Efektivitas Pengembangan E-Modul Project Based Learning pada Mata Pelajaran Instalasi Motor Listrik. Jurnal Ilmiah Pendidikan Dan Pembelajaran, 3(3). http://dx.doi.org/10.23887/jipp.v3i3.21840. 306-309.

Mahendra, E. (2017). Project Based Learning Bermuatan Etnomatematika Dalam Pembelajar Matematika. Jurnal Pendidikan Indonesia, 6(1). http://dx.doi.org/10.23887/jpi-undiksha.v6i1.9257.

Mastra, I. N. (2019). Peningkatan Kinerja Guru Dalam Penyusunan Rencana Pelaksanaan Pembelajaran (RPP) Melalui Pendampingan Klasikal Dan Individual Di SD Negeri 26 Ampenan Semester SAtu Tahun Pelajaran 2017/2018. Jurnal Ilmiah Mandala Education, 5(2). http://dx.doi.org/10.36312/jime.v5i2.755.

Mega, C., Pudjawan, K., \& Margunayasa, I. G. (2015). Analisis sikap sosial siswa kelas V pada pembelajaran dengan kurikulum 2013. Mimbar PGSD Universitas Pendidikan Ganesha, 3(1). 
http://dx.doi.org/10.23887/jjpgsd.v3i1.5631.

Mustika, D., \& Ain, S. Q. (2020). Peningkatan Kreativitas Mahasiswa Menggunakan Model Project Based Learning dalam Pembuatan Media IPA Berbentuk Pop Up Book. Jurnal Basicedu, 4(4), 1167-1175. https://doi.org/10.31004/basicedu.v4i4.518.

Mutakinati, \& Anwari. (2018). Analysis Of Students ' Critical Thinking Skill Of Middle School Through Stem Education Project-Based Learning. Jurnal Pendidikan IPA Indonesia, 7(1), 54-65. https://doi.org/10.15294/jpii.v7i1.10495.

Nkulikiyinka, P., Yan, Y., Güleç, F., Manovic, V., \& Clough, P. T. (2020). Prediction of sorption enhanced steam methane reforming products from machine learning based soft-sensor models. Energy and AI, 2. https://doi.org/10.1016/j.egyai.2020.100037.

Nugroho, R. (2018). Pengembangan Perangkat Pembelajaran Dengan Pendekatan Contextual Teaching And Learning Untuk Meningkatkan Motivasi Dan Hasil Belajar Bagi Siswa Kelas Iv Sekolah Dasar. Jurnal Bidang Pendidikan Dasar, 2(2). https://doi.org/https://doi.org/10.21067/jbpd.v2i2.2638.

Pratiwi, I. A., Ardianti, S. D., \& Kanzunnudin, M. (2018). Peningkatan Kemampuan Kerjasama Melalui Model Project Based Learning (Pjbl) Berbantuan Metode Edutainment Pada Mata Pelajaran Ilmu Pengetahuan Sosial. Refleksi Edukatika: Jurnal Ilmiah Kependidikan, 8(2). https://doi.org/10.24176/re.v8i2.2357.

Prayito. (2011). Pengembangan Perangkat Pembelajaran Matematika Humanistik Berbasis Konstruktivisme Berbantuan E-Learning Materi Segitiga Kelas VII. AKSIOMA Journal of Mathematics Education, 2(2). https://doi.org/10.26877/aks.v2i2/Septembe.37.

Pujayanti, P., Murda, I. N., \& Wibawa, I. M. C. (2013). Pengaruh Model Pembelajaran Course Review Horay Berbantuan Media Gambar Terhadap Hasil Belajar Ipa Siswa Kelas Iv Sd Gugus Viii Munduk. MIMBAR PGSD Undiksha, 1(1). http://dx.doi.org/10.23887/jjpgsd.v1i1.1341.

Revathy, G., Affan, S. Z., Suriya, M., Kumar, P. S., \& Rajendran, V. (2021). Optimization study on competence of power plant using gas/steam fluid material parameters by machine learning techniques. Materials Today: Proceedings, 32(2). https://doi.org/10.1016/j.matpr.2020.07.245.

Rusnilawati, R. (2016). Pengembangan perangkat pembelajaran matematika bercirikan active knowledge sharing dengan pendekatan saintifik kelas VIII. Jurnal Riset Pendidikan Matematika, 3(2). https://doi.org/10.21831/jrpm.v3i2.10633.

Sibaweihi, N., Patel, R. G., Guevara, J. L., Gates, I. D., \& Trivedi, J. J. (2021). Real-time steam allocation workflow using machine learning for digital heavy oil reservoirs. Journal of Petroleum Science and Engineering, 199. https://doi.org/10.1016/j.petrol.2020.108168.

Tegeh, I. M., \& Kirna, I. M. (2010). Metode Penelitian Pengembangan Pendidikan. Singaraja: Undiksha.

Thuneberg, H. M., Salmi, H. S., \& Bogner, F. X. (2018). How creativity, autonomy and visual reasoning contribute to cognitive learning in a STEAM hands-on inquiry-based math module. Thinking Skills and Creativity, 29. https://doi.org/10.1016/j.tsc.2018.07.003.

Udayana, Wirawan, \& Divayana. (2017). Pengembangan E-modul pada mata pelajaran pemrograman berorientasi objek dengan model pembelajaran Problem Based Learning Kelas VIII rekayasa perangkat lunak. Jurnal Nasional Pendidikan Teknik Informatika (Janapati), 6(2), 128-139. http://dx.doi.org/10.23887/janapati.v6i2.9373.

Wang, Y., Liu, H., \& Zhou, Y. (2021). Development of a deep learning-based model for the entire production process of steam-assisted gravity drainage (SAGD). Fuel, 287. https://doi.org/10.1016/j.fuel.2020.119565.

Wijanarko, Supardi, \& Marwoto. (2017). Keefektifan Model Project Based Learning Terbimbing untuk Meningkatkan Keterampilan Proses Sains dan Hasil Belajar IPA. Journal of Primary Education, 6(2), 120-125. https://doi.org/10.15294/jpe.v6i2.17561.

Wijayanti, N. P. A., Damayanthi, L. P. E., Sunarya, I. M. G., \& Putrama, I. M. (2016). Pengembangan E-Modul Berbasis Project Based Learning Pada Mata Pelajaran Simulasi Digital Untuk Siswa Kelas X Studi Kasus di SMK Negeri 2 Singaraja. Jurnal Pendidikan Teknologi Dan Kejuruan, 13(2), 184-197. http://dx.doi.org/10.23887/jptk-undiksha.v13i2.8526.

Wikanengsih, Nofiyanti, \& Permana. (2015). Analisis Rencana Pelaksanaan Pembelajaran (RPP) Mata Pelajaran Bahasa Indonesia (Studi Terhadap Rpp Yang Disusun Guru Bahasa Indonesia Tingkat SMP Di Kota Cimahi. Jurnal Ilmiah P2M STKIP Siliwangi P2M STKIP Siliwangi, 2(1). https://doi.org/10.22460/p2m.v2i1p106-119.170.

Wirdaningsih, S., Arnawa, I. M., \& Anhar, A. (2017). Pengembangan Perangkat Pembelajaran Matematika Dengan Pendekatan Contextual Teaching And Learning Untuk Meningkatkan Kemampuan Pemecahan Masalah Peserta Didik Kelas XI. Jurna Nasional Pendidikan Matematika, 1(2). http://dx.doi.org/10.33603/jnpm.v1i2.535.

Yerizon, Y., Putri, Y. U., Musdi, E., \& Permana, D. (2020). Efektivitas Perangkat Pembelajaran Matematika 
Berbasis Pendekatan Contextual Teaching and Learning Terhadap Kemampuan Komunikasi Matematis. AKSIOMA: Jurnal Program Studi Pendidikan Matematika, 9(1), 205. https://doi.org/10.24127/ajpm.v9i1.2305.

Yulianto, A., Fatchan, A., \& Astina, I. K. (2017). Penerapan Model Pembelajaran Project Based Learning Berbasis Lesson Study Untuk Meningkatkan Keaktifan Belajar Siswa. Jurnal Pendidikan, 2(3), 448453. http://dx.doi.org/10.17977/jptpp.v2i3.8729.

Zeptyani, \& Wiarta. (2020). Pengaruh Project-Based Outdoor Learning Activity Menggunakan Media Audio Visual Terhadap Perilaku Belajar Anak Usia Dini. Jurnal Pendidikan Anak Usia Dini Undiksha, 8(2), 69-79. http://dx.doi.org/10.23887/paud.v8i2.24740.

Zharylgassova, P., Assilbayeva, F., Saidakhmetova, L., \& Arenova, A. (2021). Psychological and pedagogical foundations of practice-oriented learning of future STEAM teachers. Thinking Skills and Creativity, 41. https://doi.org/10.1016/j.tsc.2021.100886. 